\title{
Delphi method: oracle or sound judgment?
}

\author{
R. Gunzburg ${ }^{1}$
}

Received: 5 May 2015/Revised: 5 May 2015/Accepted: 5 May 2015/Published online: 13 May 2015

(c) Springer-Verlag Berlin Heidelberg 2015

In ancient Greece, Delphi was thought to be the very center of the world. According to the legend, when Apollo slew Python, his body fell into a fissure at the site of Delphi. Over this fissure sat the priestess Pythia, and the fumes that arose from his decomposing body, brought her into a trance, allowing her to prophesize.

In medicine, outcomes measure the quality of medical care: the standard against which the end result of an intervention should be assessed. Could Pythia have prophesized outcomes? The very name Delphi method implies such a possibility!

The Delphi method, as is the case for many inventions (laser, MRI...), was first developed in the context of warfare, in casu the cold war. The idea is to create a systematic interactive forecasting method, relying on a panel of experts answering questionnaires in several rounds. After each round, a moderator presents an anonymous synthesis and justification of the experts' forecast, encouraging the experts to subsequently revise their opinions for the following round until a pre-defined end point is reached [1].

There are many reservations that have been raised in the literature on this method. In any event, the name 'Delphi'-implying an oracle—seems inappropriate for a scientific endeavor.

Outcome measures must show validity by testing precisely what they are meant to test and show reliability by not being influenced by who does the testing or when. Ideally, they must also show responsiveness by employing a scale that allows testing of change over time.

R. Gunzburg

robert@gunzburg.be

1 Cavell Spine Centre, Edith Cavell Clinic, Edith Cavell Street 32, 1180 Brussels, Belgium
Zang et al. [2] used the Delphi method to try and determine the treatment of choice in cervical radiculopathy in a Chinese environment. This well-conducted study emphasizes once more the lack of sufficient evidence we face in the field of spinal disorders.

In their paper 'Core outcome domains for clinical trials in non-specific low back pain', Chiarotto et al. [3] undertake a very important study to try and determine a core outcome set for studies on non-specific low back pain. They used the Delphi method, involving a large number of experts. Having determined which outcome domains are 'core', they aim to now determine which instruments will best be used to measure these domains. We look forward to the second leg of their groundbreaking work.

With the generalized acceptance and use of these core outcomes, their incorporation in widespread, international registries such as the Spine Tango Registry will be very useful in generating some of the answers we are seeking.

Conflict of interest None.

\section{References}

1. Rowe G, Wright G (1999) The Delphi technique as a forecasting tool: issues and analysis. Int J Forecast 15:353-375

2. Zang L, Fan N, Hai Y, Lu SB, Su QJ, Yang JC, Du P, Gao YJ (2015) Using the modified Delphi method to establish a new Chinese clinical consensus of the treatments for cervical radiculopathy. Eur Spine J. doi:10.1007/s00586-015-3856-7

3. Chiarotto A, Deyo RA, Terwee CB, Boers M, Buchbinder R, Corbin TP, Costa LO, Foster NE, Grotle M, Koes BW, Kovacs FM, Lin CW, Maher CG, Pearson AM, Peul WC, Schoene ML, Turk DC, van Tulder MW, Ostelo RW (2015) Core outcome domains for clinical trials in non-specific low back pain. Eur Spine J. doi:10.1007/s00586-015-3892-3 